APPLICATIONS IN FINANCE, INVESTMENTS, AND BANKING 


\section{Advances in Computational Economics}

\section{VOLUME 9}

\section{SERIES EDITORS}

Hans Amman, University of Amsterdam, The Netherlands

Anna Nagurney, University of Massachusetts at Amherst, USA

\section{EDITORIAL BOARD}

Anantha K. Duraiappah, European University Institute

John Geweke, University of Minnesota

Manfred Gilli, University of Geneva

Kenneth L. Judd, Stanford University

David Kendrick, University of Texas at Austin

Daniel McFadden, University of California at Berkeley

Ellen McGrattan, Duke University

Reinhard Neck, University of Klagenfurt

Adrian R. Pagan, Australian National University

John Rust, University of Wisconsin

Berc Rustem, University of London

Hal R. Varian, University of Michigan

The titles published in this series are listed at the end of this volume. 


\title{
Applications in \\ Finance, Investments, and Banking
}

\author{
Edited by \\ Diem Ho \\ IBM Management Technologies Consulting Group - Europe \\ and \\ Thomas Schneeweis \\ CISDM, School of Management, \\ University of Massachusetts
}

Springer Science+Business Media, LLC 
A C.I.P. Catalogue record for this book is available from the Library of Congress.

ISBN 978-1-4419-5062-8 ISBN 978-1-4757-3007-4 (eBook)

DOI 10.1007/978-1-4757-3007-4

Printed on acid-free paper

All Rights Reserved

C1999 Springer Science+Business Media New York

Originally published by Kluwer Academic Publishers in 1999.

Softcover reprint of the hardcover 1st edition 1999

No part of the material protected by this copyright notice may be reproduced or utilized in any form or by any means, electronic or mechanical, including photocopying, recording or by any information storage and retrieval system, without written permission from the copyright owner 


\section{Table of Contents}

Part I. Finance Overview

1. Advanced Applications in Finance: An Overview of Problems and Solution Techniques

Diem Ho

Part II. Issues in Financial Management for Financial Institutions

2. Principles for the Control of Asset Liability Management Strategies in Banks and Insurance Companies

Goren Bergendahl

Jacques Janssen

3. Asset \& Liability Management: Regulatory Guidelines on Interest Rate Risk

Control and Their Impacts on Financial Institution

Elisabetta Gualandri

4. OTC Derivatives and the 'Competitive Payments System' Debate: The Lessons from History and Implications for a Supervisory Framework

George A. Martin

Part III. Issues in Asset Management

5. A Unified Approach to Performance Attribution

Thomas K. Philips

6. Volatility

Ronald C. Heynen

Harry M. Kat 
Part IV. Issues in Investment Management

7. Diversifying Earnings Forecast Errors via Composites of Market-based, Analyst and Time-Series Predictions

Pieter Elgers

May Lo

Dennis Murray

8. The Valuation of Cross-Currency Interest-Sensitive Claims with Application to "Diff" Swaps

Simon H. Babbs 


\section{Preface and Summary}

Financial innovations have historically been driven by economic changes as well as technological progress. Today, advances in trading technology and regulatory changes, affecting banks as well as the corporate and investment community, have led to dramatic and rapid changes. Similarly, the applications of quantitative investment and computer technologies have given us a new array of tools and techniques with which to manage risk and return in asset management.

The papers contained in this volume concentrate on research and applications in three areas: mathematics and optimization in portfolio management, regulatory issues in financial product management, and investment management issues in both domestic and international markets. Each article offers a unique understanding to various issues confronting investors in the international marketplace. In "Advanced Applications in Finance: An Overview of Problems and Solution Techniques", Diem Ho offers a wide ranging survey of the state of the art in financial applications of quantitative methods. In this article, Ho gives us a sense of the range of areas which have made use of quantitative methods, as well as the power of such methods in formulating and solving problems which had been heretofore impossible to address--or otherwise addressable only by a few institutions possessing the necessary physical and human resources, such as supercomputers and specialists trained in both financial and quantitative problem solving. In so doing, Ho explains how changes in the nature of financial markets (globalization 
and deregulation) and technological advance (the widespread availability of extensive computing resources--including software as well as hardware) have combined with advances in financial theory and practice, to yield the present environment. He focuses on six specific areas: Portfolio Optimization, Asset Pricing, Risk Assessment, Securitization, Asset-Liability Management, and Data Visualization, and provides us with a discussion of both the mathematical and computing techniques that make up these application areas, as well as how those techniques have enhanced financial practice. The reader may also find the chapter as a quick refresher course in some areas of finance and mathematics. As such, it serves a useful preface to many of the other chapters contained in this book.

In their paper on asset-liability management (ALM), "Principles for the Control of Asset Liability Management Strategies in Banks and Insurance Companies," Goran Bergendahl and Jacques Janssen give us a detailed discussion of sophisticated techniques for insurance companies, banks and other financial institutions to effectively and simultaneously manage risk and return, focusing in particular on the consequences associated with interest rate risk, liquidity risk and default risk. They explain many of the short-comings of traditional approaches to ALM, which do not thoroughly address the fact that risk and returns are jointly determined, and provide a detailed framework of their own approach which directly remedies such a gap. In particular, drawing upon the mathematics of stochastic calculus, the authors give us an methodology for evaluating and selecting ALM strategies. Many explicit examples are provide to both illustrate the conceptual issues involved as well as facilitate the readers understanding of how financial institutions might actually operationalize their approach to ALM. Further, Bergendahl 
and Janssen do not neglect to provide us with their own specific recommendations on organizational and managerial elements that must be integrated into any firm's ALM system.

In her article, "Asset \& Liability Management: Regulatory Guidelines On Interest Rate Risk Control and Their Impacts on Financial Institutions," Elisabetta Gualandri offers us a broad discussion of the many regulatory issues that confront financial institutions, paying particular attention to the problem of Interest Rate Risk (IRR). Such issues have become even more acute in recent years, with increases in volatility of interest (and exchange rates), as well as the potential for financial institution missteps afforded by an international market for derivatives comprised of OTC interest rate contracts with a notional value of 28 trillion dollars. Gualandri emphasizes the need for both supervisory authorities and financial institutions to confront matters of prudential regulation with an intimate and holistic conception of actual and evolving asset and liability management practices of the financial institutions themselves--a natural and essential complement to the discussion presented in the paper by Janssen and Bergendahl. Optimal enterprise strategy has and will necessarily continue to be affected by the regulations in place, both at the national, and at supranational level (e.g., as established by the G-10 central banks through the Bank for International Settlements and associated institutions), as well as those due to be implemented, such as the BIS provisions on Market Risk. Gualandri provides us with some specific ways--at practical, (i.e. operational) as well as conceptual levels--that this may be done, as well as providing us with discussion of many related concerns. 
In his paper, "OTC Derivatives and the 'Competitive Payments System' Debate: The Lessons from History and Implications for a Supervisory Framework," George Martin offers us an analysis of the importance of monetary settlement institutions for understanding the evolution of financial markets and instruments, and in particular, the global market in over-the-counter derivative securities. In doing so, he offers an alternative to the monetary theorists who argue against the essential uniqueness of central bank backed and supervised fiat money as a viable medium of exchange, arguing that previous experiences in American economic history with multiple media of exchange have resulted in monetary instability. He argues that the U., S. Federal Reserve, and by extension other central banks, has evolved in function to eliminate monetary instability by promoting efficient and reliable settlement mechanisms, and has been so successful in such. Having developed a perspective on the nature of the settlements process, Martin takes the view that derivatives should be seen as an extension of the payments system, and thus, given the unique interest and responsibility of the Federal Reserve in supervising that system, that is this economic function of derivatives, rather than other characteristics (such as 'suitability' for commercial banks), which properly brings their supervision within the provinence of the Fed.

In this modern world of global communication and asset management, investors are also becoming increasingly sophisticated in their understanding of markets and their performance. In a "A Unified Approach to Performance Attribution", Thomas Philips describes a performance attribution methodology that can be used to analyze the performance of domestic and international equity managers and asset allocators. In 
addition, he describes methods to deal with cash flows in to and out of the portfolio, and to perform multiperiod attributions. These methods are general and can be applied to any additive single period performance attribution methodology. As with any analytic tool, the simple use of such an analysis can sometimes mislead. With a little care, though, it can give many insights into the nature of a manager's skills, facilitate the choice of a manager and the definition of his mandate, and help monitor the manager's performance on an ongoing basis.

Advances in investments have gone far beyond even that of traditional asset management and traditional asset products such as stocks and bonds. Against a backdrop of option pricing applications, Ronald Heynen and harry Kat give us a thorough analysis of the concept of asset volatility and its operationalization in option pricing. In such applications, it is typically the only parameter value that needs to be estimated in order to price options--the other values being explicitly given by the terms of the financial contract being analyzed. Conversely, if market prices of options are available, then, as Heynen and Kat show, one can infer the market's estimation of the volatility of the underlying asset. Such estimates are forward looking, and find ready application in all areas of asset pricing or management, as volatility is elemental to any notion of risk. Moreover, Heynen and Kat address the fact that asset return volatility is time varying, and in so doing provide a review of the GARCH (Generalized Auto-Regressive Conditional Heteroscedasticity) literature that currently occupies a central place in the modeling practice for financial time series. They also address the fact that the classical Black-Scholes (BS) model of optionpricing seems to be rejected as a model of how markets actually price options, since 
empirical evidence suggests that the option-implied unconditional distribution of underlying asset price dynamics requires either time-varying volatility or a departure from the assumption that the driving process behind asset prices can adequately be represented as geometric Brownian motion. The practical result--documented by Heynen and Kat--of these violations of the BS model include the fact that option prices imply a "volatility smile" (in which the implied volatility varies with the strike price of the option) or a 'term structure of volatility' (in which the expected volatility for an asset varies with the time to expiration of the option.) All told, Heynen and Kat bring us to a better understanding of the nature of asset price volatility and its impact on option pricing theory, and provide us with kind of insights that allow us to quickly put that knowledge into practice.

In investments, the foundation of equity valuation as well as investment management performance is often found in a through understanding of firms' actual and forecasted earnings. In "Diversifying Earnings Forecast Errors via Composite of Marketbased, Analyst, and Time-Series Predictions", Pieter Elgers, May Lo, and Dennis Murray show that alternative earnings forecast methods may be complementary rather than competitive. In this paper, Elgers, Lo, and Murray evaluate financial analyst, marketbased and time-series forecasts as potential complements in the construction of composite forecasts. Both relative prior error (RPE) and regression weighting schemes are examined, and results are provided separately for firms in different size groups. They conclude that RPE-weighted composites enable significant reductions in earnings prediction errors for all size groups. Regression-based composites fail to improve upon 
the prediction errors of the single-method forecasts due to pronounced temporal instability in the covariances among the forecast errors of the single-method forecasts.

One natural consequence of the increasing internationalization of securities and derivative markets is the growth in financial products designed to allow its purchaser the opportunity to take positions whose value explicitly or implicitly depends on combinations of international interest rates and exchange rates. In his paper, "The Valuation of Cross-Currency Interest-Sensitive Claims, with Application to "Diff" Swaps," Simon Babbs provides us with an analytical framework to price such assets, focusing in particular on diff swaps, instruments which allow parties to exchange cash flows based on movements in cross-currency interest rates (e.g., exchanging six-month USD Libor for 3 month DM Libor denominated in dollars). The model which Babbs develops allows for very general specification of inter-asset correlations, and through use of a one-factor (Vasicek) model of the term structure of interest rates, provides us with tractable expressions for the value of diff swaps. The essay also gives the reader substantial exposure to some very recent mathematical techniques--that are on the cusp of those used in financial theory--used in the pricing of interest and exchange rate assets and contingent claims based on those assets. In particular, it presents a sophisticated analysis of the financial questions at hand by exploiting the interrelation between the absence of arbitrage in a price system and the "risk-neutralized" martingale dynamics of prices within that system--a framework for analysis that was presaged by Black and Scholes. Readers interested in pursuing term structure modeling in this general framework should know that it has moved far from the pages of academic journals, providing, as it does, the 
basis for models used at most of the major investment banks and other large financial institutions.

It is hoped that the readers of this volume will better understand the basis behind the creation of new financial instruments and the role of computer technology, accounting, mathematics and optimization in practical financial applications. Special thanks are given to those individuals who gave of their time to review the various articles submitted for this publication. As in most endeavors, however, several individuals deserve special note. We especially thank George Martin at the Center for International Securities and Derivatives Markets for his efforts at transcribing what are difficult research articles and to the offices of Kluwer publication for their patience and support in publishing the authors' efforts.

\section{Diem Ho}

IBM Management Technologies Consulting Group - Europe

Thomas Schneeweis

CISDM, School of Management, University of Massachusetts 
Authors Background

Simon Babbs, First National Bank of Chicago, London

Goran Bergendahl, Department of Business Administration, School of Economics and Commercial Law, University of Gothenburg, Gothenburg

Pieter Elgers, School of Management, University of Massachusetts, Amherst

Jacques Jansen, Universite Libre de Bruxelles, Ecole de Commerce SOLVAY (CADEPS) et Dept. de Mathematicques, Brussels

Elisabetta Gulandri, Department of Economics Asiendale, University of Modena

Ronald Heynen, Banque Paribas, London

Diem Ho, IBM Management Technologies Consulting Group - Europe, Paris

May Lo, Western New England College, Springfield, Massachusetts

Harry Kat, Bank of America, London

George Martin, CISDM, School of Management, University of Massachusetts

Dennis Murray, University of Colorado-Denver, Denver, Colorado

Thomas Philips, Paradigm Asset Management, New York 